\title{
Determinação das atividades de lactato desidrogenase e fosfatase alcalina no soro e fluido abdominal de cães (Canis familiaris, Linnaeus, 1758) para classificação das efusões
}

\section{Activity of lactate dehydrogenase and alkaline phosphatase in the serum and abdominal fluid of dogs (Canis familiaris, Linnaeus, 1758) for classification of effusions}

Francisco Ferreira Lima Júnior, ${ }^{*}$ Keila Mara Cassiano, ${ }^{* *}$ Marcia Carolina Salomão Santos, ${ }^{* * *}$ Nayro Xavier de Alencar***

\begin{abstract}
Resumo
Este trabalho teve como objetivo mensurar as atividades das enzimas fosfatase alcalina (FA) e lactato desidrogenase (LDH) no fluido abdominal e no soro de cães, estabelecendo sua utilidade para diferenciação dos fluidos classificados como transudato, transudato modificado e exsudato. Foram utilizados 16 cães portadores de efusão abdominal, atendidos pelo setor de clínica médica de pequenos animais do Hospital Veterinário da Universidade Federal Fluminense (UFF) e demais clínicas veterinárias de Niterói e Rio de Janeiro (RJ). Foram coletadas amostras de sangue e fluido abdominal e encaminhadas para análise laboratorial. Após o processamento das amostras, quatro foram classificadas como transudatos, oito como transudatos modificados e quatro como exsudatos. A atividade da LDH no fluido e sua relação fluido/soro conseguiram diferenciar os transudatos dos transudatos modificados e exsudatos. Já a atividade sérica de LDH desses cães não possibilitou a diferenciação entre os três grupos. Os níveis de FA no fluido e no soro desses cães também não conseguiram estabelecer diferenças entre os três grupos. Em contraste, a relação fluido/soro de FA conseguiu diferenciar os transudatos dos transudatos modificados e exsudatos. Os resultados sugerem que a LDH pode ser mais eficiente como marcador bioquímico que a FA, auxiliando na classificação das efusões abdominais.
\end{abstract}

Palavras-chave: ascite, cão, marcadores bioquímicos.

\begin{abstract}
The main goal of this survey was to measure the activity of alkaline phosphatase enzymes (ALP) and lactate dehydrogenase $(\mathrm{LDH})$ in the abdominal fluid and serum to determine its availability to the differentiation of fluids classified as transudate, modified transudate and exudate. Sixteen dogs with abdominal effusion were used, admitted by the small animal medical clinic subdivision of the Veterinary Hospital at Universidade Federal Fluminense (UFF) and further veterinary clinics from Niteroi city and Rio de Janeiro state (RJ). Blood and abdominal fluid samples were collected and analyzed quickly in the laboratory. After the sample processing, four abdominal fluids were classified as transudate, eight as modified transudate and four as exudate. The activity of lactate dehydrogenase (LDH) in the fluid and its fluid/serum ratio enabled the differentiation of transudate from modified transudate and exudate. The serum activity of LDH in these dogs did not differentiate the three groups. It was not possible to determine differences between the three groups using the ALP levels in the fluid and in the serum of these dogs. However, the ALP fluid/serum ratio differentiated the transudates from the modified transudates and exudates. The results suggest that LDH may be more efficient as a biochemistry marker than ALP, assisting in the classification of abdominal effusion.
\end{abstract}

Keywords: ascite, dog, biochemistry markers.

\footnotetext{
* Programa de Pós-Graduação em Clínica Veterinária (Doutorado) - Faculdade de Medicina Veterinária e Zootecnia, Universidade de São Paulo. E-mail: guerreirovet@hotmail.com

** Departamento de Estatística - Faculdade de Matemática - Universidade Federal Fluminense. Rua Mário Santos Braga, S/N, Bairro: Valonguinho, CEP 24020-140 / Niterói - RJ. E-mail: keilamara@vm.uff.br

*** Departamento de Patologia e Clínica Veterinária - Faculdade de Veterinária, Universidade Federal Fluminense. Rua Vital Brazil Filho, 64. Niterói - RJ. CEP 24.230-340. E-mail: nayro@vm.uff.br
} 


\section{Introdução}

Ascite significa o acúmulo de fluido na cavidade peritoneal. Classicamente esta definição aplica-se aos fluidos transudativos e exsudativos, podendo ser utilizada também quando se refere ao acúmulo de sangue, quilo, urina ou bile (King e Gelens, 1992). Ressalta-se que algumas causas de ascite em cães incluem hipertensão portal, hipoproteinemia, neoplasias abdominais, peritonite, coagulopatias, traumas e obstruções na drenagem linfática (Nestor et al., 2004).

As efusões são geralmente classificadas como transudatos, transudatos modificados e exsudatos, dependendo da concentração de proteínas, contagem de células nucleadas e tipos celulares presentes (Meyer e Franks, 1993).

Em humanos, alguns parâmetros bioquímicos aferidos no fluido abdominal têm auxiliado na detecção da causa da efusão, particularmente quando diferenciam efusões neoplásicas de efusões associadas à cirrose e tuberculose (Bansal et al., 1998).

A LDH foi utilizada como marcador bioquímico de fluidos abdominais e pleurais em humanos, auxiliando na diferenciação entre transudatos e exsudatos (Paramothayan e Barron, 2002). As concentrações de FA também demonstraram seu valor, quando mensuradas no fluido abdominal de outras espécies, a exemplo dos caprinos e equinos (Nazifi et al., 2000; Saulez et al., 2004).

De acordo com Metintas et al. (1997), a FA quando mensurada no fluido pleural e no soro de humanos demonstrou ser um bom marcador bioquímico, auxiliando na diferenciação entre os grupos transudato e exsudato. A relação fluido/soro dessa enzima também possibilitou a diferenciação entre os grupos.

$O$ presente trabalho teve como objetivo mensurar as atividades de LDH e FA no fluido abdominal e no soro sanguíneo de cães, como também estabelecer a relação fluido/soro dessas enzimas, com o intuito de demonstrar a sua utilidade para diferenciação dos fluidos classificados como transudato, transudato modificado e exsudato.

\section{Material e métodos}

Foram utilizados 16 cães adultos, machos e fêmeas, de diversas raças, com idade compreendida entre três e 14 anos, e variações no peso de 2 a $36 \mathrm{Kg}$. Esses animais foram provenientes dos atendimentos ambulatoriais realizados em hospitais e clínicas veterinárias situadas nos municípios de Niterói e Rio de Janeiro (RJ). Os cães envolvidos na pesquisa não estavam sob tratamento clínico. Para as avaliações ultrassonográficas ou radiográficas do abdômen, foram adotados procedimentos para confirmação do quadro efusivo (Steyn e Wittum, 1993; Kruth, 2004).

Cada cão foi contido manualmente, procedendo-se a coleta de $3 \mathrm{~mL}$ da amostra sanguínea a partir da veia jugular, para a realização das provas bioquímicas. A centrifugação da amostra foi realizada na velocidade de $1500 \mathrm{~g}$, durante 10 minutos, em centrífuga TDL $80-2 \mathrm{~B}$ da marca Centribio, para separação do soro sanguíneo. Uma alíquota do soro foi acondicionada em frasco tipo Eppendorff ${ }^{\oplus}$, e armazenada em freezer a $-20^{\circ} \mathrm{C}$, até o momento do processamento (Serakides, 1996).
Para coleta do fluido abdominal, os cães foram colocados em decúbito lateral e contidos adequadamente. Após tricotomia e antissepsia do abdômen ventral, as amostras de fluido abdominal foram coletadas segundo a técnica descrita por Meyer et al. (1995). A amostra coletada em volume de $13 \mathrm{~mL}$ foi acondicionada em dois tubos de ensaio, um contendo anticoagulante (EDTA-10\%) e outro sem anticoagulante, destinados à realização das provas bioquímicas e citologia (Cowell et al., 1999). A amostra de fluido abdominal foi centrifugada na velocidade de $400 \mathrm{~g}$, durante 5 minutos para separação do sobrenadante. Uma alíquota do sobrenadante foi acondicionada e armazenada, de maneira similar à utilizada com o soro sanguíneo (Alleman, 2003).

A análise físico-química do fluido abdominal foi realizada conforme as técnicas descritas por Tyler e Cowell (1989) e Parry (1997). A contagem global de hemácias e células nucleadas do fluido abdominal foi obtida pelo método do hemocitômetro (Garcia-Navarro e Pachaly, 1994; Thrall et al., 2007).

O material para análise citológica foi preparado através da técnica de compressão "squash" (Tyler et al., 1999). As lâminas foram secas ao ar e fixadas em álcool metílico P.A (95\%) durante cinco minutos (Mota e Oliveira, 1999), sendo coradas em seguida pelo método de Romanowsky (Giemsa) por 30 minutos (Jörundsson et al.,1999).

Foram avaliados três grupos experimentais (GI, GII e GIII). O Gl foi composto por quatro cães com efusão abdominal que apresentaram características de transudato. Nesse caso, a concentração proteica do líquido foi inferior a $2,5 \mathrm{~g} / \mathrm{dL}$, e a contagem de células nucleadas por microlitro $(\mu \mathrm{L})$ menor que 1000 (Kolata, 1976; Shelly, 2003). Em relação ao Gll, foram selecionados oito cães com efusão abdominal, que apresentaram características de transudato modificado. O líquido desse grupo apresentou concentração proteica $\geq 2,5 \mathrm{~g} / \mathrm{dL}$, e a contagem total de células nucleadas estava entre $1000 \mathrm{e}$ 5000 células/ $\mu \mathrm{L}$ (Larkin, 1994; Shelly, 2003). Pertenceram ao GIII, quatro cães com efusão abdominal que apresentaram características de exsudato. O líquido desse grupo foi caracterizado por concentração proteica $>3,0 \mathrm{~g} / \mathrm{dL}$, e contagem de células nucleadas superior a 5000 células/ $\mu \mathrm{L}$ (Shelly, 2003).

Em um período não superior a 48 horas (Faria, 2000), uma alíquota de soro e outra do sobrenadante do líquido foram utilizadas para determinação das atividades da FA e LDH, utilizando-se os kits da marca Bioclin ${ }^{\circledR}$. Essas determinações foram feitas em analisador bioquímico semiautomático, modelo BIO 200-F.

As concentrações séricas e do fluido abdominal foram comparadas nos três grupos, como também a relação fluido/ soro foi utilizada para essa comparação. Os dados coletados foram analisados pelo programa SPSS (Statistical Package for the Social Science), versão 13.0. Todas as discussões foram realizadas ao nível de $5 \%(p$-valor $<0,05 \%)$ de significância (Arango, 2005).

A normalidade na distribuição dos dados foi testada pelo teste de Kolmogorov-Smirnov (K-S). Uma vez evidenciada a não normalidade na distribuição das variáveis, para comparar as atividades da LDH e FA no soro e no fluido, como também na relação fluido/soro dos três grupos (Gl, Gll 
e GIII), optou-se pelo teste de Kruskall-Wallis. Os testes de Mann-Whitney e Post-Hoc Student Newman-Keuls, foram utilizados para comparar a média de dois grupos independentes (GI / GII, Gl / GIII e GII / GIII), para verificar a existência de diferenças nas atividades de LDH e FA no soro e no fluido, como também na relação fluido/soro dessas enzimas.

\section{Resultados e discussão}

Foi observada alta variabilidade nas atividades séricas de LDH dentro dos grupos estudados; isto pode ter ocorrido devido à inespecificidade dessa enzima ou a uma lesão hepática preexistente nos animais (Turk e Casteel, 1997). A atividade sérica de LDH também apresentou coeficiente de variação alto em pesquisa realizada por Spak (1960), que concluiu que esta enzima não era um bom marcador bioquímico na diferenciação de enfermidades. Nesse trabalho não foi observada diferença significativa na atividade sérica da enzima LDH nos animais dos grupos I, II e III (p-valor=0,451), corroborando com Spak (1960).

Por outro lado, o teste Kruskall Wallis indicou diferença significativa ( $p$-valor $=0,008)$ na atividade da enzima LDH do fluido abdominal dos grupos. Verificou-se que o Gl foi o que apresentou no fluido abdominal atividades de LDH bem menores e significativamente diferentes em relação aos outros grupos ( $p$-valor $=0,008$ com o Gll e $p$-valor $=0,020$ com o GIII). Não houve diferença significativa entre as concentrações do Gll e GIII ( $p$ valor $=0,126)$.

Alguns trabalhos utilizando a LDH como marcador bioquímico nos fluidos pleural e abdominal de humanos (Light et al., 1972; Paramothayan e Barron, 2002), conseguiram realizar a separação entre transudatos e exsudatos. Em cães, a utilização de LDH para esta classificação demonstrou valor restrito, apenas diferenciando a origem de alguns quadros efusivos (Hirchberger e Sauer, 1991). Embora os animais dos grupos Gll e GIII não tenham sido discriminados pela concentração de LDH no fluido, no presente trabalho esta enzima demonstrou ser um bom marcador bioquímico para diferenciar significativamente pelo menos o Gl dos demais. A Figura 1 exibe, em colunas, as medianas das concentrações de LDH no soro e fluido abdominal. As barras vão do mínimo ao máximo nos valores obtidos nas análises.

As relações fluido/soro das concentrações de LDH dos três grupos (GI, GIl e GIII) apontaram diferenças significativas ( $p$ valor $=0,039)$. Demonstrou-se que o $\mathrm{Gl}$ apresenta relação fluido/soro significativamente diferente dos outros grupos, corroborando com os resultados de Light et al. (1972), que distinguiu os grupos transudato e exsudato através da relação fluido/soro de LDH. A relação fluido/soro não demonstrou dife- rença entre o Gll e GIII ( $p$-valor $=1,00)$. As principais estatísticas referentes à concentração de LDH são listadas na Tabela 1.

Ao comparar as atividades da FA nos três grupos, obteve-se p-valor de 0,258 para o teste nas concentrações séricas, e $p$-valor de 0,443 no teste comparando as concentrações no fluido. A análise desses resultados revelou que não há diferença significativa nas atividades da FA no soro e no fluido abdominal, impossibilitando a separação dos grupos por caracterização da $\mathrm{FA}$, em contraste aos resultados encontrados por Metintas et al. (1997).

Nos três grupos podemos analisar que as médias da FA no fluido encontram-se elevadas, quando comparadas com as médias das atividades enzimáticas de FA mensuradas no fluido peritoneal do pós-operatório de cães, no trabalho realizado por Bjorling et al. (1983), que apesar de atribuírem essa elevação parcialmente ao procedimento anestesiológico utilizado durante a cirurgia, não deixaram claro que o processo inflamatório pudesse levar a esse aumento. Trabalhos envolvendo outras espécies (caprinos e equinos) também demonstram aumento dessa enzima no fluido quando ocorre alguma injúria orgânica (Nazifi et al., 2000; Saulez et al., 2004). 


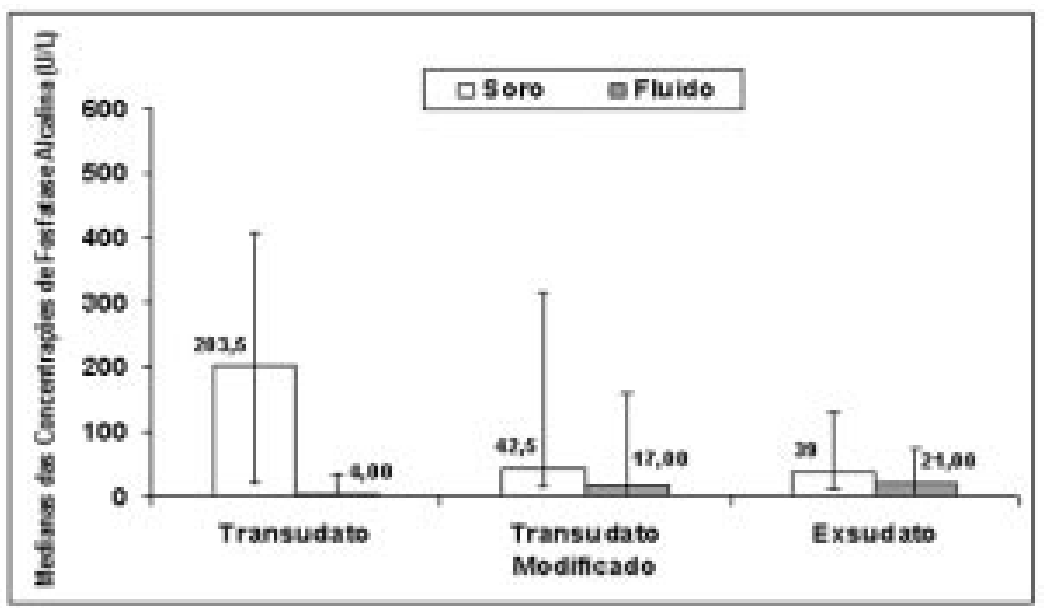

Figura 2: Medianas das atividades da Fosfatase Alcalina (FA) no soro e fluido abdominal de cães com efusões classificadas como transudato (GI), transudato modificado (GII) e exsudato (GIII). Niterói - RJ, UFF, 2008.
A Figura 2 exibe em colunas, as medianas das concentrações de FA no soro e fluido abdominal. As barras vão do mínimo ao máximo nos valores obtidos nas análises.

Quando comparadas as relações fluido/soro de FA nos três grupos (GI, Gll e GIII), obteve-se $p$-valor $=0,05$. Demonstrou-se que o $\mathrm{Gl}$ apresentou relação fluido/soro significativamente diferente dos outros grupos ( $p$-valor = 0,041 com o Gll e $p$-valor = 0,021 com o GIII). Não houve diferença significativa na relação fluido/soro entre o Gll e GIII ( $p$-valor $=1,00)$. As principais estatísticas referentes à concentração de FA são listadas na Tabela 2.

\section{Conclusões}

A determinação da LDH no fluido abdominal de cães, bem como sua relação fluido/soro pode ser utilizada para diferenciar transudato de transudato modificado e exsudato. No entanto, apenas a relação fluido/soro da FA pode ser utilizada para esse fim.

\begin{tabular}{|c|c|c|c|c|c|}
\hline Meio & Estatística & Transudato & $\begin{array}{l}\text { Transudato } \\
\text { Modificado }\end{array}$ & Exsudato & $\begin{array}{c}\text { P-valor } \\
\text { Kruskall Wallis }\end{array}$ \\
\hline \multirow{4}{*}{ Soro } & Média & 209,00 & 82,25 & 55,75 & \multirow{4}{*}{0,258} \\
\hline & Desvio-padrão & 162,00 & 98,13 & 55,84 & \\
\hline & Mediana & 203,5 & 42,5 & 39,00 & \\
\hline & Coeficiente de Variação & 0,78 & 1,19 & 1,00 & \\
\hline \multirow{4}{*}{ Fluido } & Média & 11,00 & 34,87 & 29,75 & \multirow{4}{*}{0,443} \\
\hline & Desvio-padrão & 16,06 & 52,72 & 33,36 & \\
\hline & Mediana & 4,00 & 17,00 & 21,00 & \\
\hline & Coeficiente de Variação & 1,46 & 1,51 & 1,12 & \\
\hline
\end{tabular}

\section{Referências}

ALLEMAN, A.R. Abdominal, thoracic, and pericardial effusions. Vet Clin North Am. Small Anim Pract., v. 33, n. 1, p. 89-118, 2003.

ARANGO, G.H. Bioestatística teórica e computacional. 2. ed. Rio de Janeiro: Guanabara Koogan, 2005.

BANSAL, S.; KAUR, K.; BANSAL, A.K. Diagnosing ascitic etiology on a biochemical basis. Hepatogastroenterology., v. 45, n. 23, p. 16731677, 1998.

BJORLING, D.E.; LATIMER, K.S.; ROWLINGS, C. A. Diagnostic peritoneal lavage before and after abdominal surgery in dogs. American Journal of Veterinary Research, v. 44, n. 5, p. 816-820, 1983.

COWELL, R.L.; TYLER, R.D.; MEINKOTH, J.H. Abdominal and thoracic fluid. In: . Diagnostic Cytology and Hematology of the Dog and Cat. 2. ed. St. Louis: Mosby, 1999, p.142-158.

FARIA, E.P. Influência da armazenagem de amostras de sangue nas dosagens bioquímicas e hormonais. Cader Téc Vet Zootec., n. 31, p. 21-52, 2000.

GARCIA-NAVARRO, C.E.K.; PACHALY, J.R. Técnicas hematológicas. In: . Manual de Hematologia Veterinária. São Paulo: Varela, 1994, p. 69-93.
HIRSCHBERGER, J.; SAUER, U.G. Klinisch-chemische untersuchung von körperhöhlenergüssen. Tierärz Praxis., v. 19, n. 4, p. 431-434, 1991.

JÖRUNDSSON, E.; LUMSDEN, J.H.; JACOBS, R.M. Rapid staining techniques in cytopathology: a review and comparison of modified protocols for hematoxylin and eosin, papanicolaou and romanowsky stains. Vet Clin Pat., v. 28, n. 3, p. 100-108, 1999.

KING, L.G.; GELENS, H.C.J. Ascites. Comp Cont Educ Pract Vet., v. 14, n. 8, p. 1063-1075, 1992.

KOLATA, R.J. Diagnostic abdominal paracentesis and lavage: experimental and clinical evaluations in the dog. JAm Vet Med Assoc., v. 168, n. 8, p. 697-699, 1976.

KRUTH, S.A. Distensão abdominal, ascite e peritonite. In: ETTINGER, S.J.; FELDMAN, E.C. Tratado de medicina interna veterinária: Doenças do cão e do gato. 5. ed. Rio de Janeiro: Guanabara Koogan, 2004, p. 142-144.

LARKIN, H.A. Collection and examination of body cavity fluids in animals. Vet Cytol., v. 47, p. 211-219, 1994.

LIGHT, R.W.; MACGREGOR, M.I.; LUCHSINGER, P.C.; BALL, W.C. Pleural effusions: the diagnostic separation of transudates and exsudates. Ann Intern Med., v. 77, n. 4, p. 507-513, 1972. 
METINTAS, M.; ALATAS, Ö.; ALATAS, F.; COLAK, O.; OZDEMIR, N.; ERGINEL, S. Comparative analysis of biochemical parameters for differentiation of pleural exsudates from transudates light's criteria, cholesterol, bilirubin, albumin gradient, alkaline phosphatase, creatine kinase, and uric acid. Clin Chim Acta., v. 264, n. 2, p.149-162, 1997.

MEYER, D.J.; COLES, E.H.; RICH, L.J. Avaliação das efusões. In: Medicina de laboratório veterinária: interpretação e diagnóstico. São Paulo: Roca, 1995, p. 111-115.

MEYER, D.J.; FRANKS, P.T. Effusion: classification and cytologic examination. In:__. Veterinary laboratory medicine: in practice, The Compendium Collection. New Jersey: 1993, p. 86-91.

MOTA, E.F.F.; OLIVEIRA, S.R. Diagnóstico citológico em medicina veterinária. Cader Téc Vet Zootec., n. 30, p. 29-47, 1999.

NAZIFI, S.; DEHGHANI, S.;BARZEGAR, M.R. Evaluation of cellular and biochemical parameters of blood and peritoneal fluid following enterectomy in the goat. Small Rumin Res., v. 37, n. 1-2, p. 65-71, 2000.

NESTOR, D.D.; MCCULLOUGH, S.M.; SCHAEFFER, D.J. Biochemical analysis of neoplastic versus nonneoplastic abdominal effusions in dogs. J Am Anim Hosp Assoc., v. 40, n. 5, p. 372-375, 2004.

PARAMOTHAYAN, N.S.; BARRON, J. New criteria for the differentiation between transudates and exsudates. J Clin Pathol., v. 55, n. 1, p. 69-71, 2002.

PARRY, B.W. Miscellaneous laboratory techniques. In: PRATT, P.W. Laboratory Procedures for Veterinary Technicians. 3. ed. St. Louis: Mosby, 1997, p. 561-579.

SAULEZ, M.N.; CEBRA, C.K.; TORNQUIST, S.J. The diagnostic and prognostic value of alkaline phosphatase activity in serum and peritoneal fluid from horses with acute colic. J Vet Intern Med., v. 18, n. 4 , p. 564-567, 2004
SERAKIDES, R. Colheita e remessa de material para exames laboratoriais. Cader Téc Vet Zootec., n. 16, p. 39-57, 1996.

SHELLY, S.M. Fluidos de cavidades corporais. In: RASKIN, R.E.; MEYER, D.J.; Atlas de citologia de cães e gatos. São Paulo: Roca, 2003, p.157-171.

SPAK, I. On the clinical value of chemical analysis of ascites: a study of the main proteins and some enzymes in ascites of differing etiology. Acta Chir Scand., Suppl. 261, p. 100-101, 1960.

STEYN, P.F.; WITTUM, T.E. Radiographic, epidemiologic, and clinical aspects of simultaneous pleural and peritoneal effusions in dogs and cats: 48 cases (1982-1991). J Am Vet Med Assoc., v. 202, n. 2, p. 307-312, 1993.

THRALL, M.A.;BAKER, D.C.; CAMPBELL, T.W. Coleta e processamento de amostras e análise das opções de serviços laboratoriais. In: Hematologia e bioquímica clínica veterinária. São Paulo: Roca, 2007, p. 37-42.

TURK, J.R.; CASTEEL, S.W. Clinical biochemistry in toxicology. In: KANEKO, J. J.; HARVEY, J.W.; BRUSS, M.L. Clinical Biochemistry of Domestic Animals. 5. ed. California: Academic Press, 1997, p. 829-843.

TYLER, R.D.; COWELL, R.L. Evaluation of pleural and peritoneal effusions. Vet Clin North Am. Small Anim Pract., v. 19, n. 4, p. 743768, 1989

TYLER, R.D.; COWELL, R.L.;BALDWIN, C.J. Introduction. In: COWELL, R.L.;TYLER, R.D.; MEINKOTH, J.H. Diagnostic Cytology and Hematology of the Dog and Cat. 2. ed. St. Louis: Mosby, 1999, p.1-19. 